Discussion

\title{
An artificial opposition between grammaticality and frequency: comment on Bornkessel, Schlesewsky, and Friederici (2002)
}

\author{
Gerard Kempen $^{\text {a,b,*}}$, Karin Harbusch ${ }^{\mathrm{c}}$ \\ ${ }^{a}$ Department of Psychology, Leiden University, Leiden, The Netherlands \\ ${ }^{\mathrm{b}}$ Max Planck Institute for Psycholinguistics, Nijmegen, The Netherlands \\ ${ }^{c}$ Computer Science Department, University of Koblenz-Landau, Koblenz, Germany
}

Received 3 June 2003; accepted 4 July 2003

\begin{abstract}
In a recent Cognition paper (Cognition 85 (2002) B21), Bornkessel, Schlesewsky, and Friederici report ERP data that they claim "show that online processing difficulties induced by word order variations in German cannot be attributed to the relative infrequency of the constructions in question, but rather appear to reflect the application of grammatical principles during parsing” (p. B21). In this commentary we demonstrate that the posited contrast between grammatical principles and construction (in)frequency as sources of parsing problems is artificial because it is based on factually incorrect assumptions about the grammar of German and on inaccurate corpus frequency data concerning the German constructions involved.
\end{abstract}

(C) 2003 Elsevier B.V. All rights reserved.

Keywords: Frequency; Grammaticality judgments; Word order; Parsing difficulty; German

In their experimental study, Bornkessel, Schlesewsky and Friederici (2002) (henceforth BSF), measured event-related brain potentials in participants who were reading subordinate clauses such as those in $(1 \mathrm{a}-\mathrm{d})$. In $(1 \mathrm{a}, \mathrm{b})$, the finite verb takes a dative object, and in $(1 \mathrm{c}, \mathrm{d})$ the object has accusative case. Due to the flexibility of German word order, the nominative Subject NP is allowed to precede or to follow the dative or

\footnotetext{
* Corresponding author. Cognitive Psychology Unit, Leiden University, P.O. Box 9555, 2300 RB Leiden, The Netherlands.

E-mail addresses: kempen@fsw.leidenuniv.nl (G. Kempen), harbusch@uni-koblenz.de (K. Harbusch). 
accusative object. It is standardly assumed that the constituent orders in (1a) and (1c) are canonical (unmarked) while those in (1b) and (1d) are non-canonical (marked).
(1) a. Nominative-dative
$\ldots$ dass der Jäger dem Gärtner
$\ldots$ that $[\text { the hunter }]_{\mathrm{NOM}}$ [the gardener $]_{\mathrm{DAT}}$
'... that the hunter helps the gardener.'
hilft
b. Dative-nominative
... dass dem Jäger der Gärtner
$\ldots$ that $[\text { the hunter }]_{\mathrm{DAT}} \quad[\text { the gardener }]_{\mathrm{NOM}}$
'... that the gardener helps the hunter.'
c. Nominative-accusative ... dass der Jäger den Gärtner
$\ldots$ that $[\text { the hunter }]_{\mathrm{NOM}} \quad[\text { the gardener }]_{\mathrm{ACC}}$
'... that the hunter visits the gardener.'
d. Accusative-nominative
... dass den Jäger der Gärtner
$\ldots$ that $[\text { the hunter }]_{\mathrm{ACC}}$ [the gardener $]_{\mathrm{NOM}}$ visits
'... that the gardener visits the hunter.'
helps
hilft
helps
besucht
visits
besucht

The grammar of German also allows canonical clause-initial dative NPs. BSF refer to examples such as (2a), the passive version of (1b). Although passivization of (1b) leaves dative case intact, its position is as unmarked as the nominative NP in (2b), the passive version of $(1 \mathrm{~d})$.
(2) a. ... dass dem Jäger
... that $[\text { the hunter }]_{\mathrm{DAT}}$
'... that the hunter is helped'
b. ... dass der Jäger
$\ldots$ that $[\text { the hunter }]_{\mathrm{NOM}}$
'... that the hunter is visited'

$\begin{array}{ll}\begin{array}{l}\text { geholfen } \\ \text { helped }\end{array} & \begin{array}{l}\text { wird } \\ \text { is }\end{array} \\ \begin{array}{l}\text { besucht } \\ \text { visited }\end{array} & \text { wird } \\ & \text { is }\end{array}$

From these facts of German word order, in conjunction with well known on-line ERP effects of human parsing, BSF derive the prediction that clause-initial accusative NPs such as in (1d) will elicit a negative deflection in the ERP as compared with the nominative or dative clause-initial NPs in $(1 \mathrm{a}-\mathrm{c})$, which can be interpreted as occupying a canonical position. For clauses such as (1b), this is possible if the processor initially adopts the canonical passive analysis of the clause. However, this analysis "can only be maintained until the second argument is encountered, when it becomes clear that this initial analysis is not correct. Thus, a reanalysis should be observed in the form of a positive deflection in the ERP” (p. B25). Both predictions were indeed confirmed by the data: a negatively deflected ERP signal for accusatives, but not for datives, in comparison with nominatives; a positivity in the ERP response to the second NP in dative-nominative strings as compared to the second NP in nominative-dative strings.

BSF argue that these ERP effects cannot be explained in terms of the relative frequencies of the three word order patterns (nominative-initial, dative-initial and accusative-initial). They base this conclusion on a frequency study of word order patterns in the W-PUB corpus of the Mannheimer Institut für deutsche Sprache (http:// www.ids-mannheim.de). They counted the occurrences of subordinating conjunction dass followed by either the nominative article der, the dative article dem, or the accusative article den. They observed that dass der strings occurred much more 
frequently than dass dem, and that the strings dass dem and dass den were about equally frequent. According to BSF, the equiprobability of the latter two strings suggests that dative NPs occur about as often in clause-initial position as accusative NPs; ergo, frequency cannot explain the differential ERP responses to these two NP types. If frequency were causally involved in this effect, clause-initial datives should elicit the same negativity - quod non.

We do not intend to question the ERP data reported by BSF. Our commentary concerns their interpretation of the positivity elicited by dative-nominative sequences, and the corpus frequency data they present. We will discuss both issues in turn.

Initial dative NPs occur not only in passive clauses (2a), they may also belong to active clauses headed by verbs like gehören 'belong', gefallen 'please', passieren 'happen' and many others, as witnessed by the examples in (3). Crucially, the ordering of these datives before the nominative Subject NPs is unmarked in BSF's definition of this term: "The word order of a sentence is referred to as unmarked if this sentence can be felicitously uttered in the absence of any constraining context".

(3) a. weil mir der Garten gehört (ex. (50a) in Wunderlich, 1997)

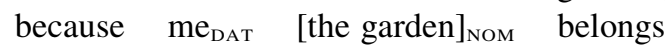

'because the garden belongs to me'

b. weil mir der Roman gefällt (ex. (50b) in Wunderlich, 1997) because me DAT $\left._{\text {[the novel }}\right]_{\mathrm{NOM}}$ pleases

'because the novel pleases me'

c. daß unserem Nachbarn etwas schreckliches passiert ist (ex. (2) in Den

that [our neighbour $]_{\mathrm{DAT}}$ [something terrible $]_{\text {NOM }}$ happened has

Besten, 1985)

'that something terrible has happened to our neighbour'

The canonical status of dative-nominative strings in sentences such as in (3) undermines BSF's account of the positivity they observed in readers who are processing the nominative NP in these strings. The fact that the grammar generates these strings implies that readers cannot be expected to initiate a reanalysis in response to seeing the nominative NP. Below we suggest another tentative explanation for the positivity.

In order to verify BSF's frequency counts, we determined the incidence of the various word order patterns at issue in the NEGRA II corpus, a German 'treebank' that has become available recently (Skut, Krenn, Brants, \& Uszkoreit, 1997; for recent information, see http://www.coli.uni-sb.de/sfb378/negra-corpus/negra-corpus.html). The corpus contains about 20,000 written sentences that have been syntactically annotated in great detail. In this corpus we collected all finite subordinate clauses that are introduced by a subordinating conjunction and contain a dative NP in isolation, or a combination of a dative and/or an accusative NP in addition to a nominative NP (see Table 1, middle column). Because, as is well known, the ordering options of pronominal and nonpronominal ("full") NPs are vastly different, we kept NPs headed by a personal or reflexive pronoun separate from the rest. The former NPs we call "pronominal"; the latter "full". As in BSF's experiment all NPs were full in this sense, we determined the incidence of full clause-initial NPs: see the rightmost column in Table 1. Addition of all initial nominatives, 
initial datives and initial accusatives in this column yields frequencies similar to those reported by BSF: 573 nominatives versus 21 datives and one accusative. This pattern fits BSF's description of their corpus data: in clause-initial position, full nominatives (BSF's dass der strings) are much more frequent than datives (dass dem) and accusatives (dass den), while datives and accusatives in this position are about equally infrequent.

Does this imply that BSF were right after all in rejecting a frequency-based account of their ERP data? Closer inspection of the data in Table 1 reveals that their conclusion is premature. Consider the pair of rows with nominative-accusative and accusativenominative strings. There is only one case where a full accusative NP precedes the nominative Subject, against 513 cases with nominative first. Compare this to the pair of rows with nominative-dative and dative-nominative strings. Here, the 20 initial datives have only 43 counterparts. The latter proportion is significantly higher than the former $\left(\chi^{2}=150.4, P \ll 0.0005\right)$. This implies that it is much more likely for a full dative than for a full accusative to precede the Subject - in agreement, of course, with the canonicity of the dative-nominative ordering in the gefallen-type clauses mentioned in (3) above.

Apparently, although initial datives and initial accusatives both are much less frequent than initial nominatives, they cannot simply be lumped together. A frequency account of the negativity effect for the first NP could run as follows. Seeing a full clause-initial accusative NP following a subordinating conjunction, the syntactic processor can safely predict a nominative NP. However, on the basis of past experience, it also knows that full accusatives preceding the nominative are extremely rare (occurring in less than one-fifth of $1 \%$ of all transitive clauses). On the other hand, a full dative NP preceding the predictable nominative occurs in no less than $32 \%$ of all clauses containing both these NPs.

Although the number of 573 full clause-initial nominatives reported above is much higher than both the mere 21 datives and one accusative, the difference between the latter

Table 1

Frequency of relevant permutations of nominative, dative, and accusative NPs in finite subordinate clauses of the NEGRA II corpus

\begin{tabular}{lcc}
\hline Constituent order & All clauses & First NP full \\
\hline Dative only & 2 & 1 \\
Nominative-dative & 61 & 43 \\
Dative-nominative & 38 & 20 \\
Nominative-accusative & & 513 \\
Accusative-nominative & 792 & 1 \\
& 115 & 14 \\
Nominative-dative-accusative & & 3 \\
Nominative-accusative-dative & 29 & 0 \\
Dative-nominative-accusative & 8 & 0 \\
Accusative-nominative-dative & 11 & 595 \\
Total & 6 & \\
\hline
\end{tabular}


two numbers appears to represent a genuine difference. When we repeated BSF's dass dem and dass den searches in the W-PUB corpus (see http://www.ids-mannheim.de/zdv/ cosmas $2 /$ ), we found the two strings indeed to lie in the same frequency range. However, closer inspection of the dass den occurrences in a random sample of 300 sentences extracted from the corpus revealed that about $95 \%$ of the dens introduced a plural dative, not a singular accusative. The article den is ambiguous between singular accusative masculine and plural dative (in any gender). It follows that the observations in the NEGRA II corpus are paralleled by the W-PUB corpus: the incidence of initial accusatives is much less frequent than that of initial datives. Parenthetically, the fact that der has several uses other than nominative masculine article does not affect the overall picture: the nonnominative occurrences comprise only $3 \%$ of the der tokens.

How can we explain the positivity in the ERP response to nominative NP in dativenominative strings as compared to nominative-dative strings? As stated earlier, the reanalysis interpretation offered by BSF cannot hold in view of the unmarked nature of dative-first clauses of the gefallen type. As is well known, a powerful factor influencing the order of the major constituents of a clause is the (in)animacy of the referents (e.g. see McDonald, Bock, \& Kelly, 1993 and the references therein). We therefore determined, for the clauses extracted from the NEGRA II corpus, whether the relevant NPs refer to animate or inanimate entities. In the $99(=61+38$; see Table 1) clauses that contain a dative and a nominative in any order (without accusative), there are 47 with one unambiguously animate and one unambiguously inanimate NP. In 42 of these, the animate NP precedes the inanimate one. This attests to a strong "animacy first" tendency. Of the 38 dative-nominative clauses we found in the corpus, 34 have inanimate nominative NPs, most of them referring to an abstract concept. (The four exceptions are clauses with two animate NPs where the initial dative is pronominal.) For the participants in BSF's ERP experiment, this implies that after the full animate initial dative (e.g. dem Jäger 'the hunter') they anticipated an inanimate or even abstract nominative subject NP. ${ }^{1}$ The observed positivity may very well have been a response to the falsification of this expectation. It thus appears that a frequency-based account of the second part of BSF's experimental results is feasible.

More generally, the opposition that BSF create between the grammaticality and the frequency of syntactic constructions has the odds stacked against itself. In a recent experimental study on "gradient grammaticality", Keller (2000) has shown that the six possible permutations of nominative, dative and accusative NPs in ditransitive German complement clauses elicit clearly different grammaticality ratings. As shown in Table 1, four of these orders were observed in the NEGRA II corpus, and the two remaining ones have zero frequency. The Spearman rank-order correlation between the overall grammaticality ratings reported by Keller and the NEGRA II frequencies of the six permutations amounts to $0.90(P<0.025)$.

To sum up, BSF have overlooked an important class of dative constructions in German and misinterpreted the corpus frequency data they collected. We conclude that BSF have

\footnotetext{
${ }^{1}$ We assume, in the absence of explicit mention by BSF, that the relevant NPs in the subordinate clauses were all animate, as suggested by the examples that the authors supply in their Table 1. If not, their ERP results could have been affected by a confound between constituent order and animacy.
} 
prematurely ruled out a frequency interpretation of their ERP results and failed to prove their case against the convergence of grammaticality and frequency.

\section{References}

Bornkessel, I., Schlesewsky, M., \& Friederici, A. D. (2002). Grammar overrides frequency: evidence from the online processing of flexible word order. Cognition, 85(2), B21-B30.

Den Besten, H. (1985). The ergative hypothesis and free word order in Dutch and German. In J. Toman (Ed.), Studies in German grammar. Dordrecht: Foris.

Keller, F (2000). Gradience in grammar: experimental and computational aspects of degrees of grammaticality. $\mathrm{PhD}$ Thesis, University of Edinburgh.

McDonald, J. L., Bock, K., \& Kelly, M. H. (1993). Word and world order: semantic, phonological and metrical determinants of serial position. Cognitive Psychology, 25, 188-230.

Skut, W., Krenn, B., Brants, T., \& Uszkoreit, H. (1997). An annotation scheme for free word order languages. Proceedings of the Fifth Conference on Applied Natural Language Processing (ANLP), San Francisco, CA: Morgan Kaufmann.

Wunderlich, D. (1997). Cause and the structure of verbs. Linguistic Inquiry, 28, 27-68. 